\title{
Factors Influencing the Use of Wireless Sensor Networks in the Irrigation Field
}

\author{
Loubna HAMAMI $^{1}$, Bouchaib NASSEREDDINE ${ }^{2}$ \\ Computer, Networks, Mobility and Modeling Laboratory \\ Faculty of Sciences and Technology, Hassan 1st University, Settat, Morocco
}

\begin{abstract}
Battle control, natural disasters discovery, water monitoring, smart homes, agricultural applications, health care, weather forecasts, smart buildings, intrusion detection, medical devices, and more are the application areas of wireless sensor networks (WSNs). WSNs can help bring about revolutionary changes in important areas of our world. As a result, this technology has become a particularly interesting technology, which can be used to meet the specific requirements of a particular application because of its distinctive characteristics. In this context, WSNs are a promising approach in the agricultural sector and irrigation in particular for overcoming the world's major problems (e.g., the global water crisis). When implementing WSN in the irrigation field, many factors, like limited sensor node resources, limited sensor node power, costs, hardware constraints, and type of deployment environment, must be taken into account in order to improve WSN performance and achieve the desired results. In this paper, we will study and analyze the main factors that affect WSNs in the irrigation field. We will also provide a set of measures and solutions that need to be taken to overcome the challenges of deploying a WSN in irrigation. In this regard, we will also highlight several factors for improvement to achieve an efficient and consistent irrigation system using WSN.
\end{abstract}

Keywords-Cost; energy consumption and management; irrigation; smart irrigation; wireless sensor network; WSN deployment

\section{INTRODUCTION}

The need to control and supervise hostile or remote environments, reducing the size, the availability of a wide range of diverse sensor types. In addition to the three basic functions performed by the sensor network [1], [2], i.e., computation, detection, and communication, and the features provided by WSNs [3]-[5], e.g., dynamic topology, scalability, self-monitoring, and flexibility. All this has led to the involvement and development of WSNs as a potential application in various domains [6]-[8] like medical, industry, environment, agriculture, and military. Wireless sensor networks have been deployed in several agricultural applications to support agricultural services [2], [9], [10] (e.g., pesticide spraying, irrigation, horticulture, and fertilization) and improve agricultural production. One of the most vital services in the agricultural domain is irrigation, as irrigation is an indispensable element in this domain and plays a very significant role in improving yields and raising agricultural production [11], [12]. Therefore, irrigation is considered one of the most agricultural services where WSNs are applied successfully to realize numerous gains and provide economical and effective solutions for water utilization efficiency and water saving, thus helping to alleviate the world water crisis [13].

WSNs have been widely used in the irrigation field, and this usage has been greatly appreciated in recent years. A set of research and works focused on the application of WSN to control and manage irrigation practices has been identified from the literature and discussed in [13]. Avatade and Dhanure [14] have developed an automated irrigation system using WSN, an ARM microcontroller, and GPRS. This system is designed based on an integrated platform that uses the ARM microcontroller to control the water irrigation system. It can measure and monitor the soil moisture level and temperature through multiple ARM microcontroller-based wireless sensor nodes. Moreover, it enables remote monitoring of the status of the sensors used. Applications for irrigation systems using WSN and ZigBee have been proposed in [15]-[18]. The system proposed by Angelopoulos et al. [16] consists of IRIS motes employed for electro-valves control and TelosB motes equipped with EC-5 and SHT11 sensors that monitor a set of environmental conditions. Domestic irrigation was demonstrated in this work. An automatic irrigation system was proposed by Chikankar et al. [17] based on monitoring a set of the parameters through the usage of WSN and ZigBee. This includes LM-35, SY-HS-220, and soil moisture sensors that measure temperature, air humidity, and soil moisture. Other applications of WSN have been proposed in irrigation systems using GPRS and ZigBee technologies in [19], [20]. An automated irrigation system using WSN and other technologies to optimize and manage water use for agricultural crops was proposed by Gutiérrez et al. [19]. This system is composed of a control unit to store, evaluate, and identify the collected data, and to manage the automatic activation of irrigation using a developed. It is also composed of a distributed wireless network with numerous temperature and moisture sensors to monitor and control soil parameters. A sprinkler irrigation automation system using a WSN was designed by Nagarajan and Minu [20]. Besides, this system uses ZigBee technology for transmitting data and GPRS technology for storing and analyzing data. A system for improving the management of a variable rate irrigation system based on WSN has been presented that uses a system for identifying the criteria for placement of moisture sensors [21]. In [22], a WSN-based automated irrigation system has been proposed, explaining the workflow of the suggested system and illustrating the different relationships and interactions between the elements of this system. Utilizing GSM, Raspberry Pi, and Wi-Fi technologies, an automatic water supply system has been proposed to well control a WSN-based irrigation system [23]. In this system, a 
set of sensors is used to monitor and detect the soil moisture, soil water level, and daylight intensity. The measured data is sent as a digital signal via Wi-Fi to the Raspberry Pi. The use of smartphones in WSN-based irrigation systems has also been presented in [24], [25]. An automated irrigation sensor was developed by Jagüey et al. [25], which allows the capture and processing of digital soil images based on the use of smartphones. An application for smartphones was also developed by Bartlett et al. [24] with the aim of extending the use of cloud-based irrigation scheduling. This app provides a quick visualization of weather measurements and soil water deficit. Decision support systems for an irrigation system based on WSN have also been presented in [26], [27]. Khan et al. [27] presented a WSN-based decision support system for efficient water use. Irrigation management and outlier detection system using WSN that helps farmers to control the irrigation procedures of crops. A low-cost decision support system was also proposed by Viani et al. [26] to control the efficiency of the irrigation system and thereby save water.

The use of wireless sensor networks supports different areas of human life, including irrigation service practices. Nevertheless, a variety of factors influence the implementation and design of WSNs [28], like limited sensor node resources, limited sensor node power, costs, hardware constraints, and the type of environment. As a result, researchers are confronted with many issues and problems such as power consumption, location, architecture, deployment, and security [29]-[31] when implementing this type of network. Similarly, when implementing WSN in the irrigation field, we find that many factors are influencing this application that needs to be taken into consideration to improve the performance of WSN and achieve the desired results. However, available studies have not comprehensively and accurately addressed the factors affecting the use of wireless sensor networks in irrigation. To this end, this study aims to identify, study, and analyze the main factors that influence WSNs in the irrigation field. It also aims to provide a set of measures and solutions to be followed to overcome the challenges of designing and deploying a WSN in irrigation, while identifying improvement factors to achieve an efficient and consistent irrigation system using WSN. In this way, and through this work, we address the gaps in this area by presenting a study on the main factors affecting wireless sensor networks in the irrigation field. To conduct this study, the following research questions were considered: What are the main factors to consider when designing a wireless sensor network in the irrigation field? What measures and solutions should be taken? Are there any factors for improvement to achieve an efficient and consistent irrigation system using WSN?

Many studies and works have been presented in the irrigation field based on wireless sensor networks in recent decades. Therefore, it is significant to pay attention to the many factors that affect the use of WSNs in irrigation to improve the performance and achieve the desired results. The purpose of this paper is to provide a study and analysis of the main factors affecting WSN in the irrigation field. The paper is structured as follows. Section 1 provides an introduction. In Section 2, we present and explain the wireless sensor network technology. In Section 3, we highlight WSN technology's importance in the irrigation field by showing the advantages of using this technology in irrigation. In Section 4, we identify, study, and analyze the main factors that need to be considered when designing a WSN in the irrigation field, while proposing a set of measures and solutions that need to be taken. In Section 5, we present a discussion and synthesis. A series of improvement factors in this context are presented in Section 6. Finally, Section 7 concludes the paper.

\section{SENSORS AND WIRELESS SENSOR NETWORK}

\section{A. Wireless Sensor Network}

WSNs are composed of a large number of detection elements, called sensor nodes, which communicate through wireless communication with each other for information interchange and processing in cooperation. Sensor nodes are widely deployed near or within the being studied phenomenon that are low-cost, autonomous, and low-power multifunctional nodes [28]. A WSN is a network of nodes that can together reveal the physical environment, especially remote or hostile environments, to control and monitor such environments. In general, the sensor network achieves three fundamental functions [1], [2]:

- Sensing and Detection; the nodes collect the necessary data.

- Calculation via programs, microcontroller, hardware, and algorithm.

- Communication; the nodes communicate between them and with base station as well as base station communicates to the controller.

In the WSN [28], [32]-[35], the sensor nodes are dispersed over the field in a sensor area where each node utilizes its capabilities to detect, collect, and route data to generate a global view of the monitored area. The collected data is digitized and these values are routed directly or through other nodes according to a multiple hop architecture to a collection point, called a base station, for further treatment. The base station also functions as a gateway node whenever there is a requirement to connect to the external network for decisionmaking and data analysis. Fig. 1 illustrates the architecture of WSN in agricultural applications.

\section{B. WSNs vs. Ad-hoc Networks}

The WSN is a particular kind of Ad-hoc network. However, there are several reasons that make the difference between traditional wireless Ad-hoc networks and WSNs [36], [37]. The majority of Ad-hoc networks rely on the any-to-any communication model, while wireless sensor networks primarily are based on the communication model many-to-one. The nodes of the wireless sensor network collaborate to reach a targeted objective, whereas in an Ad-hoc network each node has its goal. WSN's topology is dynamic with frequent changes. The number of nodes in WSN is significantly higher than in Ad-hoc. Sensor nodes do not have any global identification (e.g., IP addresses) unlike nodes in Ad-hoc networks. 


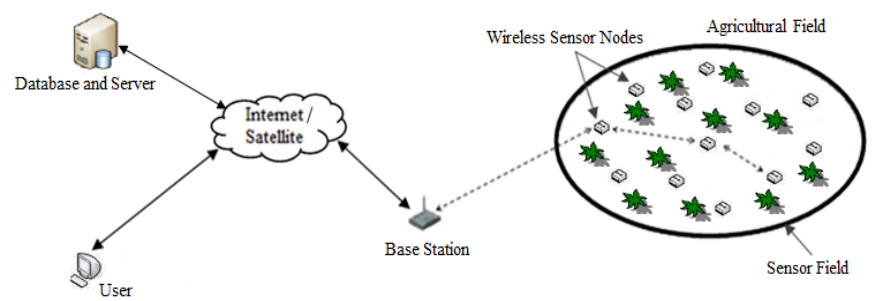

Fig. 1. Wireless Sensor Network Architecture for Agricultural Applications.

In addition, the energy consumption for sensor nodes is a determining factor, since these nodes have irreplaceable power sources because of their unassisted remote use in hostile environments. Unlike traditional Ad-hoc networks, the factor of the energy consumption is of secondary importance, since the batteries of the mobile units used can be easily replaced.

\section{WSN Characteristics}

Certain of the key features of WSN [3], [5], [13] that have made it a potential tool in numerous agricultural services (e.g., pesticide spraying, fertilization, and irrigation) are as follows:

- Collaboration between sensor nodes to reach a target objective,

- Capacity to deal with node failures,

- Capacity to adapt to different environments,

- Heterogeneity of nodes deployed in WSN,

- Little or no infrastructure,

- Ability to operate unattended in remote or hostile areas,

- Dynamic topology,

- Detection and wireless communication,

- Scalability,

- Simple to utilize,

- A high number of sensor nodes, i.e., from a few tens to thousands.

\section{Sensor Nodes}

As already mentioned above in Section 2.1, WSN is considered a distributed network of small-sized and inexpensive nodes having computing and processing resources. A sensor node is a microelectronic and microelectromechanical system that detects or measures a physical attribute (e.g., temperature and humidity) in a controlled environment and converts it into signals for monitoring and transmission [13], [28]. In general, sensor nodes emerge as miniaturized autonomous systems with advanced sensation capabilities and they are the core elements of WSN.

Since the sensor node is used in various applications, the appropriate choice of nodes requires many parameters such as the type of event to be detected, the nature of the event, the monitored environment, the nature of the signal emitted, and the cost.
As shown in Fig. 2, sensor node comprises four basic units [38], [39]:

- A sensing unit: This unit includes two subunits an Analog/Digital Converter (ADC) and a sensor. Sensor gets measurements of the monitored environment. An ADC converts the measured attribute and transmits it to the processing unit. This is the core unit of a sensor node.

- A processing unit: This unit is composed of a processor (i.e., computing unit) that perform simple calculations for collaboration with other nodes, in addition to a memory (i.e., storage unit) that integrates a specific operating system. The processing unit also ensures the analysis of the detected data.

- A transmission unit: This unit is used to connect the sensor node to WSN. It is responsible for all receptions and transmissions of acquired data in WSN through a wireless communication medium. It may be radio frequency type, e.g., MICA2 [40], or optical type, e.g., Smart Dust [41].

- A power unit: This unit is considered one of the critical elements of the sensor node. Each node is equipped with a battery to power all its components. Because of the small size of the node, the node battery is limited and generally irreplaceable.

Sensor node can add optional modules, e.g., an external memory, a location system, and a mobilization module, as well as its main components (listed above) if required. Fig. 2 shows the different components of a sensor node.

\section{AdVANTAGES OF WSN IN THE IRRIGATION FIELD}

The use of WSN in the agriculture sector is now reaching an advanced level. There are many potential applications of WSN in the field of irrigation. In the following, we highlight the main advantages of utilizing WSNs in irrigation.

\section{A. Water Savings}

The traditional irrigation practices employed only aim to control water distribution to the required places without compromising water needs, thereby losing a large amount of water in each irrigation process [11]. While we note that, the main objective of using WSNs in the irrigation field is to assure rational and efficient utilization of water, thereby achieving significant water savings.

Numerous works and research have proven that WSN is an ideal way to realize important water savings. Gutiérrez et al. [19] have shown that the utilization of WSN can lead to significant water savings in comparison to traditional irrigation practices of up to $90 \%$. In another study conducted by González-Briones et al. [43], a $15.06 \%$ reduction in water consumption has been reported in automotive irrigation processes thanks to the use of WSN and the multi-agent system. Tests realized by Katyara et al. [44] have also reported successful results regarding the reduction of water utilized for irrigation, saving about 2150 cusecs of water per year. Other tests suggested by Difallah et al. [45] indicate a $28.51 \%$ water consumption reduction. 


\section{B. Increasing Yields and Improving the Quality of Agricultural Production}

When the right timing of irrigation is well defined, there is great potential to increase yields and improve the quality of agricultural production. While any delay in irrigation can lead to losses ranging from US\$ 62 / ha to US\$ 300 / ha [46]. Thus, another objective of using WSNs in the irrigation field is to determine the irrigation requirements in a particular area at the right time, thereby increasing yields and improving the quality of agricultural production.

The results of Abd El-kader and El-Basioni [47] showed an increase in potato yields and a 2 billion pounds loss was compensated in a year through the utilization of WSN in potato fields. Tests carried out by Katyara et al. [44] have also showed positive results in terms of increasing the productivity of agricultural land, i.e., an increase of about 20 to 25\%. In another work by Khan and Kumar [48], it has been reported that the use of a mobile sink in WSN to supervise fields of ambient crops helps to increase crop yields. Nagarajan and Minu [20] have also concluded that a soil characteristics surveillance system utilizing a wireless sensor network to automate the sprinkler irrigation could improve yields with high quality and control water supply.

\section{Savings in Labor, Money, and Energy}

Traditional irrigation systems on most farms require a lot of labor, money, and energy to operate properly. Farmers are always trying to undermine these three factors. The many benefits of the WSN have allowed it to provide cost-effective and efficient strategies to improve and support irrigation systems [13]. Thus, another objective of using WSN in the field of irrigation is to offer economical and efficient solutions, thereby achieving savings in labour, money, and energy.

Experimental studies were conducted by Khan and Kumar [48] to monitor ambient crop fields using a mobile sink in WSN. It was reported that reduction in energy consumption was 0.0115 Joules in the network. Işik et al. [50] have shown that important savings in energy and costs can be realized. Tests carried out by Nikolidakis et al. [51] have also showed an improvement in the lifetime of the WSN using the Equalized Cluster Head Election Routing Protocol, i.e., up to 1825 minutes.

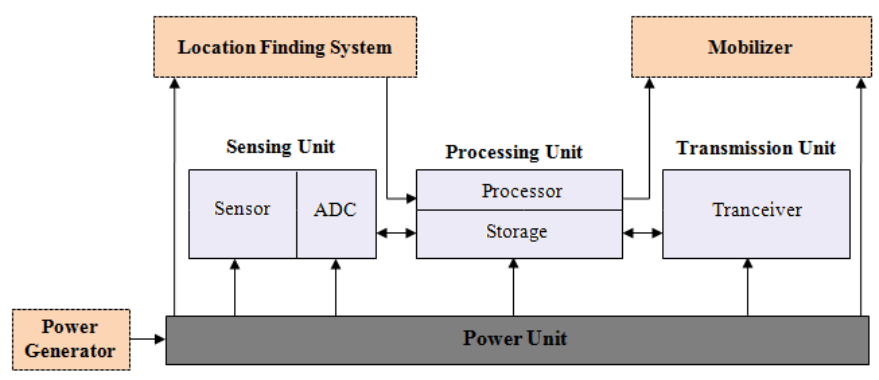

Fig. 2. Sensor Node Architecture.

\section{FACTORS AfFECTING WSNS IN THE FIELD OF IRRIGATION}

The recent years have been marked by a radical shift in the agricultural domain. Thanks to this change, new solutions have been found to develop and improve this domain, while solving its problems. The WSN is widely used successfully in various agricultural services, especially in irrigation service. This is mainly due to the importance of having an automated and accurate irrigation system, which helps maintain water resources and enhance the performance and efficiency of irrigation [13].

Nevertheless, in many scenarios, sensor nodes can be located in an unsupervised and open environment. In addition, agriculture can be practiced in agricultural fields of several hundred hectares and can encompass different climates, resources, and lands, which poses many implementation and design challenges. In this section, we discuss and analyze the main factors that need to be considered when designing WSN in the irrigation field, while proposing a set of measures and solutions to be taken. Fig. 3 shows the main factors affecting wireless sensor networks in irrigation.

\section{A. Placement of Sensor Node}

The placement of sensor nodes according to the demanded needs is one of the critical factors in the design and implementation of WSN in the field of irrigation. It serves a very important role in ensuring that the wireless sensor network operates reliably and independently. Therefore, great care should be taken when placing the sensor nodes in the area to be irrigated, so that the sensor is placed at the proper location and height to measure the parameters without obstructions and in such a way that the area to be irrigated must be completely covered. In addition, suitable devices (i.e., fixture) must be installed to support the nodes to avoid the node position change that could result from rainwater, water currents, and strong winds.

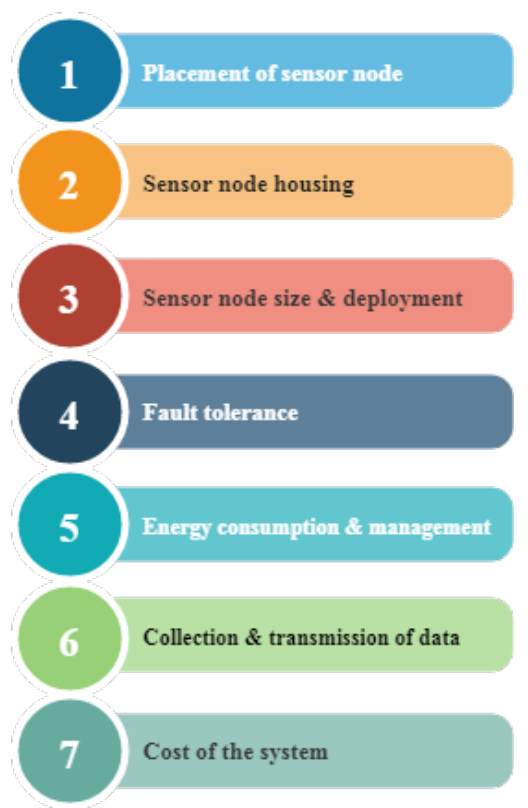

Fig. 3. Main Factors Affecting WSN in the Irrigation Field. 
In the area to be irrigated, soil moisture sensors should be placed, for example, as near to the soil as possible to obtain precise measurements, thus starting the irrigation process if the soil moisture is lower than the threshold values. Whereas air temperature sensors should be in an elevated location to correctly measure air temperature. Moreover, to manage properly the position of each node in the area to be irrigated, an appropriate method of deploying sensor nodes in WSN is necessary.

\section{B. Sensor Node Housing}

In the area to be irrigated, the deployed sensor nodes may be damaged due to human or animal abuse and may also be subject to a variety of harsh environmental conditions, e.g., strong winds, extreme heat, extreme cold, high pressure, and rainwater. Therefore, the sensor nodes must be enclosed in a protective housing that enables them to withstand the abovementioned conditions as much as possible.

In addition, the housing used must be adapted and designed in such a way that its internal components never exceed a temperature higher than that which the nodes' batteries can withstand under realistic circumstances. It is recommended to utilize a means of internal temperature control and doublewalled construction in the housing used to improve the efficiency of irrigation systems based on WSNs [52].

\section{Sensor Node Size and Deployment}

The size of the sensor node is another factor that plays a very important role in the design and implementation of WSNs in the field of irrigation. Therefore, that it must be small and suitable for deployment in the area to be irrigated.

To increase the performance of WSN-based irrigation systems, an appropriate method of deploying sensor nodes is necessary to manage correctly the position of each node in the area to be irrigated. The deployment of sensor nodes can be deterministic or random [53]-[55]. With deterministic deployment, sensor nodes propagate into pre-defined locations. Random deployment enables sensor nodes to be randomly deployed, typically in large-scale areas with inaccessible or unknown details. Deployment in WSN of large numbers of nodes makes these nodes vulnerable to failure. Thus, maintaining the sensor network topology before, during, and after deployment is a very complicated task that requires good management [28].

\section{Fault Tolerance}

Another critical factor in the design and implementation of WSNs in the field of irrigation is fault tolerance. Fault tolerance is the ability to retain the functionalities of the sensor network in the event of a failure, due to a fault in one or more nodes, without interruption [28], [56]. Given that in the area to be irrigated, a large number of sensor nodes are deployed in an open environment where these nodes may be damaged and/or fail. Sensor node failure in a WSN can arise for many reasons [57].

Sensor node dislocation, transmission link instability, environmental interference, battery depletion, defective sensor calibration, physical damage due to mishandling by humans or animals in agricultural land, software problems, extreme environmental conditions, and failure of the node hardware components are among the important reasons that can cause node failure in a WSN-based irrigation system. Such failures, nevertheless, should not affect the functioning of the entire network, based on the fault tolerance principle that aims at improving the reliability and availability of WSNs [58]. Different fault-tolerance strategies, including clustering-based mechanisms, deployment-based mechanisms, and redundancybased mechanisms, enhance network reliability [59]. Moreover, in large-scale deployments, data aggregation and topology management plans must be fault-tolerant.

In several irrigation scenarios [19], [20], [60], solarpowered sensor nodes were used to decrease the risk of node failure caused by battery depletion. In addition, in [19], node fault tolerance and communication failure were included for irrigation. The default irrigation program is followed, in the event of a problem.

\section{E. Energy Consumption and Management}

In WSN, a sensor node is composed mainly of four basic units: a sensing unit, a transmission unit, a power unit, and a processing unit. Event recognition and data transmission and processing are the main tasks of every sensor node [28]. An extra task of data routing can also be performed when it is a multi-hop network. Each of these functions consumes a lot of power. Typically, a sensor node has a restricted and limited power source, such as lithium or alkaline batteries, so the lifetime of a sensor node is largely dependent on the lifetime of the battery. Since a sensor node's battery supplies limited energy, it is critical to make sure that the power consumption of the node elements must be at a certain minimum. Minimizing the power consumption of the transmission unit, especially because it requires higher power consumption than other sensor node elements, can help alleviate this problem [51].

Energy is also an important factor in the design and implementation of WSN. Therefore, the management of energy is an essential part of any system that relies on wireless sensor networks, including irrigation systems. An adequate strategy of energy management (i.e., mechanisms and algorithms) can be implemented in both software and hardware t to prolong the life of the battery by several additional months.

In irrigation scenarios, longer sensor node life can be achieved by also taking into account the use of available energy harvesting solutions [61]-[63] like wind power, thermal power, and solar power when designing WSN-based irrigation systems, a solution considered to be costly. Besides, sensor nodes can operate with replaced batteries because they are usually well-defined in terms of location and access [64].

\section{F. Collection and Transmission of Data}

In every detection, measurement, transmission, and processing of data, energy is expended, thus using up a large part of the battery life. Therefore, it is necessary to program improved and effective data aggregation techniques and sampling rates to ensure that energy is not wasted while collecting useful and pertinent data. Furthermore, acquiring data frequently will send a massive number of packets and this rapidly depletes the batteries. The data acquisition sampling 
rate in the field of irrigation is generally not high. Nevertheless, it can be modified depending on the resources available for irrigation, the type of crops to be irrigated, and the environment.

To reduce the number of transmissions, a strategy for data transmission can also be developed, which saves energy, so that this strategy can involve intelligent data transmission, such as aggregated or modified values, and local storage of data in sensor nodes. In addition, implementing a sleep/wake-up feature can improve the performance of the network through energy savings, so that transmitters are only woken up when necessary. Reliable communication links require sensor nodes to be located close to each other to guarantee reliable multi-hop communication. Nevertheless, the characteristics of the land to be irrigated can be an obstacle to such reliable communication.

\section{G. Cost of the System}

In general, the final user, i.e., the farmer, looks at the cost and if he can bear it. Therefore, the budget for an irrigation system based on WSN is seen as one of the key priorities towards efficient utilization of the WSN. The total cost of sensor node hardware and software is a very significant factor when designing a WSN in the irrigation field.

Sensor node design for irrigation applications must be inexpensive while showing good performance. Therefore, it is always preferable to design a low-cost application so that it is available for usage by the markets of low and middle-income countries (LMIC) through minimizing the cost of software and hardware and optimizing system output [10].

\section{SYNTHESIS AND DISCUSSION}

Traditional irrigation is the common method used by the majority of farmers to irrigate agricultural land, which lacks efficient use of available resources (e.g., water). While smart irrigation is a knowledge-based method that offers flexible and reliable irrigation possibilities to farmers. It allows adapting irrigation schedules and durations to meet the specific needs of each crop through real-time monitoring. These systems greatly improve the efficiency of irrigation water use and reduce labor and time, etc.

To develop and improve irrigation systems, a range of needs and requirements must be taken into consideration including:

- It is necessary to collect soil and crop information,

- Weather information should also be collected,

- It must gather information on crop growth,

- There are different types of crops in a single field,

- Water requirements for irrigation vary depending on crop needs,
- The needs of each crop vary according to soil and weather conditions,

- Proposal and development of proactive solutions for the irrigation system,

- The condition of irrigation system equipment and components should be monitored.

- The location of irrigation system components should also be monitored.

To achieve this objective (i.e., improvement and development of irrigation systems), it is necessary to find a solution that can automate these systems and allows intelligent decision-making in order to obtain an application and processing with a parallel and distributed feature.

Sensors are the most commonly used devices in the physical and environmental data collection scenario. Especially in the field of irrigation, sensors are used to measure and detect different data according to the necessities [42] (e.g., sensors are used to measure water level, temperature sensors, humidity sensors, soil moisture sensors, and density sensors). The detected and collected data by sensors make it possible to characterize and identify the controlled environment and their status. These data are very useful for developing and improving irrigation systems. Therefore, the wireless sensor network is considered one of the most useful technologies in various applications when it is necessary to collect and process data from the environment, and thus WSN can play a vital role in irrigation management [2], [9], [10], [49] and obtain several benefits according to all the specific characteristics of this network. All of this leads us to consider WSN as a highpriority way to collect, process, and monitor critical information and react to various situations in irrigation systems [13].

The WSN-based irrigation system includes several techniques and tools utilized to automate and monitor irrigation processes in real-time. Fig. 4 shows an illustration of an automated irrigation system using WSN and its components, which we suggested in our previous work [22].

WSNs have attracted worldwide attention in recent years, making them widely and successfully used in various irrigation systems. Above, we have discussed and analyzed several key factors to consider when deploying and designing WSN in agricultural lands to be irrigated, some of which are cost, node location, energy consumption and management, sensor node size, and fault tolerance, as well as a set of measures to overcome these. In Table I, we summarize a set of factors and proposed measures to overcome the challenges of designing and deploying a WSN in the irrigation field. 


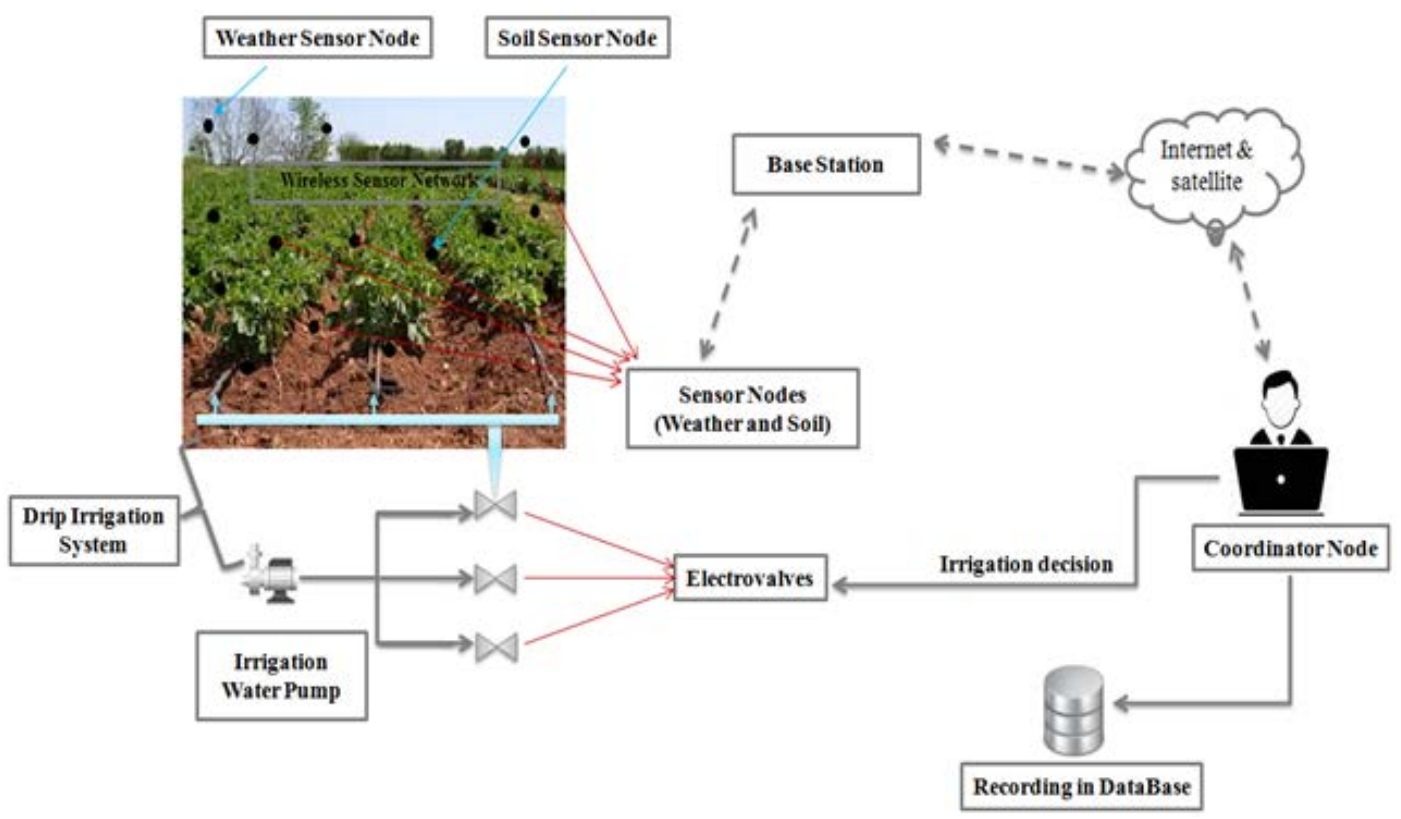

Fig. 4. Schematic Diagram of the Design for an Automated Irrigation System using WSN [22].

TABLE I. FACTORS AFFECTING WSN IN IRRIGATION AND PROPOSED MEASURES

\begin{tabular}{|c|c|c|}
\hline Factors influencing & Causes of problems & Measures / Proposed solutions \\
\hline Placement of Sensor Node & $\begin{array}{l}\text { - Sensor nodes incorrectly placed in the area to be } \\
\text { irrigated } \\
\text { - Change of sensor node position after deployment }\end{array}$ & $\begin{array}{l}\text { - Place the sensor node in the appropriate position and height } \\
\text { - Installing node support devices to prevent any change in position } \\
\text { - Appropriate deployment method for sensor nodes to correctly } \\
\text { manage the position of each node }\end{array}$ \\
\hline Sensor node housing & $\begin{array}{l}\text { Damage to deployed sensor nodes due to human or } \\
\text { animal abuse } \\
\text { - Exposure of deployed sensor nodes to extreme } \\
\text { environmental conditions (e.g. strong winds and } \\
\text { rain) }\end{array}$ & $\begin{array}{l}\text { - Enclosing the sensor node in a protective housing } \\
\text { - Design of the housing used in such a way that the internal contents } \\
\text { of this do not reach very high temperatures } \\
\text { - Use of an internal temperature control system } \\
\text { - Use of a double-walled construction }\end{array}$ \\
\hline $\begin{array}{l}\text { Sensor node deployment and } \\
\text { size }\end{array}$ & $\begin{array}{l}\text { - Node size } \\
\text { - Network deployment problem } \\
\text { - Dynamic network topology }\end{array}$ & $\begin{array}{l}\text { - Sensor node should be designed small and suitable to be deployed } \\
\text { in the area to be irrigated } \\
\text { - Appropriate deployment method for sensor nodes } \\
\text { - Random deployment / Deterministic deployment } \\
\text { - Topology maintenance of the sensor network before, during and } \\
\text { after deployment }\end{array}$ \\
\hline Fault tolerance & $\begin{array}{l}\text { - Sensor node dislocation } \\
\text { - Communication failure } \\
\text { - Physical damage \& Blockage } \\
\text { - Resource depletion (e.g., energy) } \\
\text { - Extreme environmental conditions } \\
\text { - Environmental interference }\end{array}$ & $\begin{array}{l}\text { - } \text { Clustering-based mechanisms } \\
\text { - Redundancy-based mechanisms } \\
\text { - Deployment-based mechanisms } \\
\text { - Tolerance of data aggregation and topology management schemes } \\
\text { in large-scale deployment } \\
\text { - Use of solar-powered sensor nodes to reduce node battery depletion }\end{array}$ \\
\hline $\begin{array}{l}\text { Energy consumption and } \\
\text { management }\end{array}$ & $\begin{array}{l}\text { - Data detection } \\
\text { - Data processing } \\
\text { - Data transmission } \\
\text { - Data routing } \\
\text { - Restricted and limited power source }\end{array}$ & $\begin{array}{l}\text { - Appropriate energy management strategy to prolong the life of the } \\
\text { battery } \\
\text { - Utilization of available energy harvesting solutions such as wind, } \\
\text { thermal, and solar energy } \\
\text { - Sensor nodes with replaced batteries }\end{array}$ \\
\hline $\begin{array}{l}\text { Collection and transmission } \\
\text { of data }\end{array}$ & $\begin{array}{l}\text { - Data detection } \\
\text { - Too much power consumption by the transmission } \\
\text { unit } \\
\text { - Unreliable communication links due to the } \\
\text { characteristics of the land to be irrigated }\end{array}$ & $\begin{array}{l}\text { - Data aggregation techniques and sampling rates } \\
\text { - Data transmission strategy to reduce the number of transmissions } \\
\text { - Implementation of a sleep/wake mode for sensor nodes } \\
\text { - Placement of sensor nodes in close proximity to each other to } \\
\text { ensure reliable multi-hop communication }\end{array}$ \\
\hline Cost of the system & High cost of hardware and software used & $\begin{array}{l}\text { - Design of low-cost, high-performance sensor nodes for irrigation } \\
\text { applications } \\
\text { - Reduction of software and hardware costs }\end{array}$ \\
\hline
\end{tabular}




\section{IMPROVEMENT FACTORS}

Looking ahead, we must pay more attention to several factors related to irrigation solutions based on wireless sensor networks to achieve an efficient and consistent irrigation system. Below, we highlight the most important of these factors, as shown in Fig. 5.

\section{A. Efficient use of Energy}

As mentioned in Section 4.5, an important issue in irrigation systems using wireless sensor networks is the management of energy. Therefore, future solutions must also become more energy efficient through the integration of intelligent algorithms to ensure a longer lifetime of the system.

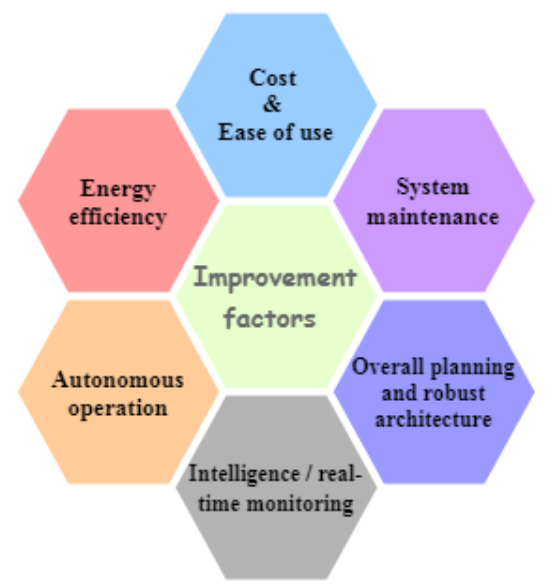

Fig. 5. Key Improvement Factors Associated with WSN-based Irrigation Solutions.

\section{B. Cost}

The high materials, programs, and systems costs related to wireless sensor networks, where equipment imported from abroad is used, is the major obstacle to the utilization of WSN in irrigation in LMICs. Therefore, we see an urgent need for cost-effective solutions to raise the application of WSN in irrigation to enhance its widespread utilization and access among farmers and stakeholders. In this context, current efforts in development and research should focus on decreasing software and hardware costs while at the same time improving system performance, which would decrease the total cost of a WSN-based irrigation system; thus, making these systems available to markets in LMICs.

\section{System Maintenance}

As mentioned earlier, the high overall cost of an irrigation system based on a WSN is one of the primary barriers to the widespread use of WSN in the field of irrigation. In addition to lowering the software and hardware costs used in wireless sensor networks, low system maintenance is required. An irrigation system based on a wireless sensor network must be designed with maintenance as low as possible, which will definitely reduce the average total cost over the long term.

\section{Autonomous Functioning}

Autonomous functioning is a very important feature that allows for simple and advanced operation in most WSN-based irrigation applications, especially in remote areas to be irrigated. Therefore, future WSN-based irrigation solutions must incorporate the ability to continue to operate autonomously without control while extending the period of autonomous operation for a longer period.

\section{E. Intelligence Factor and Real-time Monitoring}

Many crops are sensitive to climatic conditions, which require farmers to closely and continuously monitor changing weather conditions to avoid unexpected problems in the farmland to be irrigated. Thus, in addition to an autonomous functioning, future solutions for WSN-based irrigation must also be developed with inherent intelligence with real-time monitoring capability to interact proactively to meet a variety of challenges such as yield improvement, real-time response, and energy conservation.

\section{F. Ease of use}

In most cases, the final users of irrigation applications are nontechnical individuals. Therefore, future irrigation solutions based on the WSN should provide simple, easy-to-use applications for effective communication with the end-user. Besides, elements of these solutions, such as the communication interface, must be comprehensible, simple, and easy to operate.

\section{G. Comprehensive Planning and Robust Architecture}

Because of the large number of different nodes distributed over the WSN, it must be deployed on farmland to be irrigated according to a carefully defined plan. In future irrigation solutions based on the WSN, comprehensive planning and robust fault tolerant architecture, taking into account the structure of the farmland and the needs of the farmers, will be essential to ensure long-term operation while minimizing costs and improving system performance.

\section{CONCLUSION}

Irrigation is a context-rich field in which the potential for utilizing wireless sensor network technology lies very large. Adapting irrigation systems that use WSNs on a large scale necessitates paying attention to many factors that affect the use of WSN in irrigation, in order to efficiently use available resources (e.g., water) while improving performance and achieving desired results. This paper attempted to address the gaps in this area by presenting a study on the main factors affecting wireless sensor networks in the irrigation field, as we have not found studies that accurately and adequately address the factors that affect this type of application. The present paper presents a study and an analysis of the main factors that influence WSN in the irrigation field. It presents a set of measures and solutions that need to be followed to overcome the challenges of designing and deploying WSN in irrigation. A number of improvement factors have also been identified to achieve an efficient and consistent irrigation system using WSN. In addition, the importance of WSN technology in irrigation was highlighted by outlining the advantages of this application.

\section{REFERENCES}

[1] L. Hamami and B. Nassereddine, "Integration of irrigation system with wireless sensor networks: prototype and conception of intelligent irrigation system," In Lecture Notes in Engineering and Computer Science, vol. 2238, pp. 56-62, Newswood Limited, 2018. 
[2] A. Ur Rehman, A. Z. Abbasi, N. Islam, and Z. A. Shaikh, "A review of wireless sensors and networks' applications in agriculture," Computer Standards \& Interfaces, vol. 36, no. 2, pp. 263-270, 2014.

[3] S. Mishra and H. Thakkar, "Features of WSN and Data Aggregation techniques in WSN: A Survey,” Int. J. Eng. Innov. Technol. (IJEIT), vol. 1, no. 4, pp. 264-273, 2012.

[4] P. Bakaraniya and S. Mehta, "Features of wsn and various routing techniques for wsn: a survey," International Journal of Research in Engineering and Technology, vol. 1, no. 3, pp. 349-354, 2012.

[5] M. S. Manshahia, "Wireless sensor networks: a survey," International Journal of Scientific \& Engineering Research, vol. 7, no. 4, pp. 710-716, 2016.

[6] R. E. Mohamed, A. I. Saleh, M. Abdelrazzak, and A. S. Samra, "Survey on wireless sensor network applications and energy efficient routing protocols," Wireless Personal Communications, vol. 101, no. 2, pp. 1019-1055, 2018.

[7] T. Arampatzis, J. Lygeros, and S. Manesis, "A survey of applications of wireless sensors and wireless sensor networks," Proceedings of the 2005 IEEE International Symposium on, Mediterrean Conference on Control and Automation Intelligent Control. IEEE, pp. 719-724, 2005.

[8] J. A. Stankovic, A. D. Wood, and T. He, "Realistic applications for wireless sensor networks," Theoretical Aspects of Distributed Computing in Sensor Networks, Monographs in Theoretical Computer Science, An EATCS Series, Chapter 25, Springer-Verlag Berlin Heidelberg, pp. 835-863, 2011.

[9] D. Thakur, Y. Kumar, A. Kumar, and P. K. Singh, "Applicability of wireless sensor networks in precision agriculture: A review," Wireless Personal Communications, vol. 107, no. 1, pp. 471-512, 2019.

[10] T. Ojha, S. Misra, and N. S. Raghuwanshi, "Wireless sensor networks for agriculture: the state-of-the-art in practice and future challenges," Comput. Electron. Agric. vol. 118, pp. 66-84, 2015.

[11] L. Hamami and B. Nassereddine, "Towards a smart irrigation system based on wireless sensor networks (WSNs)," In : Proceedings of the 1st International Conference of Computer Science and Renewable Energies - Volume 1: ICCSRE, ISBN 978-989-758-431-2, pp. 433-442, SciTePress Digital Library, 2018.

[12] FAO, IFAD, UNICEF, WFP and WHO. The state of food security and nutrition in the world 2018: Building climate resilience for food security and nutrition. Rome, FAO, 2018.

[13] L. Hamami and B. Nassereddine, "Application of wireless sensor networks in the field of irrigation: A review," Comput. Electron. Agric., vol. 179, pp. 105782, 2020.

[14] S. S. Avatade and S. P. Dhanure, "Irrigation system using a wireless sensor network and GPRS," International Journal of Advance Research in Computer and Communication Engineering, vol. 4, no. 5, pp. 521524, 2015.

[15] M. Dursun, and S. Ozden, "A wireless application of drip irrigation automation supported by soil moisture sensors," Scientific Research and Essays, vol. 6, no. 7, pp. 1573-1582, 2011.

[16] C. M. Angelopoulos, S. Nikoletseas, and G. C. Theofanopoulos, "A smart system for garden watering using wireless sensor networks," In: Proceedings of the 9th ACM international symposium on Mobility management and wireless access, pp. 167-170, 2011.

[17] P. B. Chikankar, D. Mehetre, and S. Das, "An automatic irrigation system using ZigBee in wireless sensor network,” In: 2015 International Conference on Pervasive Computing (ICPC). IEEE, pp. 1-5, 2015.

[18] Y. Zhou, X. Yang, L. Wang, and Y. A. Ying, "wireless design of lowcost irrigation system using ZigBee technology,” In: 2009 International Conference on Networks Security, Wireless Communications and Trusted Computing. IEEE, vol. 1, pp. 572-575, 2009.

[19] J. Gutiérrez, J. F. Villa-Medina, A. Nieto-Garibay, and M. Ángel PortaGándara, "Automated irrigation system using a wireless sensor network and GPRS module,” IEEE Trans. Instrum. Meas., vol. 63, no. 1, pp. 166-176, 2014.

[20] G. Nagarajan and R. I. Minu, "Wireless soil monitoring sensor for sprinkler irrigation automation system," Wireless Personal Communications, vol. 98, no. 2, pp. 1835-1851, 2018.
[21] W. Zhao, J. Li, R. Yang, and Y. Li, Y., "Determining placement criteria of moisture sensors through temporal stability analysis of soil water contents for a variable rate irrigation system," Precision Agriculture, vol. 19, no. 4, pp. 648-665, 2018.

[22] H. Loubna and N. Bouchaib, "Wireless sensor network application for intelligent irrigation system," Journal of Advanced Research in Dynamical and Control Systems, vol. 12 (3 Special Issue), pp. 163-173, 2020.

[23] A. Imteaj, T. Rahman, M. K. Hossain, and S. Zaman, "IoT based autonomous percipient irrigation system using raspberry Pi,” In: 2016 19th International Conference on Computer and Information Technology (ICCIT). IEEE, pp. 563-568, 2016.

[24] A. C. Bartlett, A. A. Andales, M. Arabi, and T. A. Bauder, "A smartphone app to extend use of a cloud-based irrigation scheduling tool,” Computers and Electronics in Agriculture, vol. 111, pp. 127-130, 2015.

[25] J. G. Jagüey, J. F. Villa-Medina, A. López-Guzmán, and M. A. PortaGándara, "Smartphone irrigation sensor," IEEE Sensors journal, vol. 15, no. 9, pp. 5122-5127, 2015.

[26] F. Viani, M. Bertolli, M. Salucci, and A. Polo, "Low-cost wireless monitoring and decision support for water saving in agriculture," IEEE Sensors Journal, vol. 17, no. 13, pp. 4299-4309, 2017.

[27] R. Khan, I. Ali, M. Zakarya, M. Ahmad, M. Imran, and M. Shoaib, "Technology-assisted decision support system for efficient water utilization: A real-time testbed for irrigation using wireless sensor networks,” IEEE Access, vol. 6, pp. 25686-25697, 2018.

[28] L. Hamami and B. Nassereddine, "A study of the main factors affecting wireless sensor networks,” In: 2019 Third International conference on IoT in Social, Mobile, Analytics and Cloud (I-SMAC). IEEE, pp. 211215, 2019.

[29] A. J. Swati and R. Priyanka, "Wireless sensor network (WSN): Architectural design issues and challenges," International Journal on Computer Science and Engineering, vol. 2, no. 9, pp. 3089-3094, 2010.

[30] E. P. K. Gilbert, B. Kaliaperumal, and E. B. Rajsingh, "Research issues in wireless sensor network applications: A survey,” International Journal of Information and Electronics Engineering, vol. 2, no. 5, pp. 702, 2012.

[31] S. Sharma, R. K. Bansal, and S. Bansal, "Issues and challenges in wireless sensor networks," In 2013 International Conference on Machine Intelligence and Research Advancement. IEEE, pp. 58-62, 2013.

[32] M. Tubaishat and S. K. Madria, "Sensor networks: an overview,” IEEE Potentials, vol. 22, no. 2, pp. 20-23, 2003.

[33] I. F. Akyildiz, W. Su, Y. Sankarasubramaniam, and E. Cayirci, "A survey on sensor networks," IEEE communications magazine, vol. 40, no. 8, pp. 102-114, 2002.

[34] J. Yick, B. Mukherjee, and D. Ghosal, "Wireless sensor network survey,” Computer networks, vol. 52, no. 12, pp. 2292-2330, 2008.

[35] I. F. Akyildiz and M. C. Vuran, Wireless sensor networks. Vol. 4. John Wiley \& Sons, 2010.

[36] C. Perkins, Ad hoc networks. Reading: Addison-Wesley, 2000.

[37] V. Mhatre and C. Rosenberg, "Design guidelines for wireless sensor networks: communication, clustering and aggregation," Ad hoc networks, vol. 2, no. 1, pp. 45-63, 2004.

[38] I. F. Akyildiz, W. Su, Y. Sankarasubramaniam, and E. Cayirci, "Wireless sensor networks: a survey," Computer networks, vol. 38, no. 4, pp. 393-422, 2002.

[39] M. A. Matin and M. M. Islam, "Overview of wireless sensor network," Wireless Sensor Networks-Technology and Protocols, pp. 13, 2012.

[40] Crossbow, MICA2 Datasheet. [Online]. Available on: http://www.investigacion.frc.utn.edu.ar/sensores/equipamiento/wireless/ MICA2_Datasheet.pdf, accessed December 2020.

[41] Kristofer, Pister, SmartDust. [Online]. Available on: http://robotics.eecs.berkeley.edu/ pister/SmartDust/, accessed December 2020.

[42] S. A. Kumar and P. Ilango, "The impact of wireless sensor network in the field of precision agriculture: a review," Wireless Personal Communications, vol. 98, no. 1, pp. 685-698, 2018. 
[43] A. González-Briones, Y. Mezquita, J. A. Castellanos-Garzón, J. Prieto, and J. M. Corchado, "Intelligent multi-agent system for water reduction in automotive irrigation processes,” Procedia Computer Science, vol. 151, pp. 971-976, 2019.

[44] S. Katyara, M. A. Shah, S. Zardari, B. S. Chowdhry, and W. Kumar, "WSN based smart control and remote field monitoring of Pakistan's irrigation system using SCADA applications," Wireless Personal Communications, vol. 95, no. 2, pp. 491-504, 2017.

[45] W. Difallah, K. Benahmed, B. Draoui, and F. Bounaama, "Linear optimization model for efficient use of irrigation water," International Journal of Agronomy, vol. 2017, 2017.

[46] G. Vellidis, M. Tucker, C. Perry, C. Kvien, and C. Bednarz, "A realtime wireless smart sensor array for scheduling irrigation," Comput. Electron. Agric., vol. 61, no. 1, pp. 44-50, 2008.

[47] S. M. Abd El-kader and B. M. M. El-Basioni, "Precision farming solution in Egypt using the wireless sensor network technology,” Egyptian Informatics Journal, vol. 14, no. 3, pp. 221-233, 2013.

[48] T. H. F. Khan and D. S. Kumar, “Ambient crop field monitoring for improving context based agricultural by mobile sink in WSN,” Journal of Ambient Intelligence and Humanized Computing, vol. 11, no. 4, pp. 1431-1439, 2020.

[49] L. Ruiz-Garcia, L. Lunadei, P. Barreiro, and I. Robla, “A review of wireless sensor technologies and applications in agriculture and food industry: state of the art and current trends," Sensors, vol. 9, no. 6, pp. 4728-4750, 2009.

[50] M. F. Işik, Y. Sönmez, C. Yilmaz, V. Özdemir, and E. N. Yılmaz, "Precision Irrigation System (PIS) using sensor network technology integrated with IOS/Android application,” Applied Sciences, vol. 7, no. 9, pp. 891, 2017.

[51] S. A. Nikolidakis, D. Kandris, D. D. Vergados, and C. Douligeris, "Energy efficient automated control of irrigation in agriculture by using wireless sensor networks," Computers and Electronics in Agriculture, vol. 113, pp. 154-163, 2015.

[52] J. Balendonck, J. Hemming, B. A. J. Van Tuijl, L. Incrocci, A. Pardossi, and P. Marzialetti, "Sensors and wireless sensor networks for irrigation management under deficit conditions (FLOW-AID),” 2008.

[53] H. Subir, G. Amrita, S. Sanjib, D. Avishek, and D. Sipra, "A lifetime enhancing node deployment strategy in WSN," In International
Conference on Future Generation Information Technology. Springer, Berlin, Heidelberg, pp. 295-307, December 2009.

[54] S. Mini, S. K. Udgata, and S. L. Sabat, "Sensor deployment and scheduling for target coverage problem in wireless sensor networks," IEEE sensors journal, vol. 14, no. 3, pp. 636-644, 2013.

[55] G. Tuna, T. V. Mumcu, K. Gulez, V. C. Gungor, and H. Erturk, "Unmanned aerial vehicle-aided wireless sensor network deployment system for post-disaster monitoring,” In International Conference on Intelligent Computing. Springer, Berlin, Heidelberg, pp. 298-305, July 2012.

[56] I. F. Akyildiz and M. C. Vuran, Factors influencing WSN design, 2010.

[57] M. Younis, I. F. Senturk, K. Akkaya, S. Lee, and F. Senel, “Topology management techniques for tolerating node failures in wireless sensor networks: A survey,” Comput. Networks, vol. 58, no.1, pp. 254-283, 2014.

[58] H. Alwan and A. Agarwal, “A survey on fault tolerant routing techniques in wireless sensor networks,” In 2009 Third International Conference on Sensor Technologies and Applications, IEEE, pp. 366371, 2009.

[59] G. Kakamanshadi, S. Gupta, and S. Singh, "A survey on fault tolerance techniques in wireless sensor networks,” In 2015 international conference on green computing and internet of things (ICGCIoT). IEEE, pp. 168-173, October 2015.

[60] N. G. Shah, U. B. Desai, I. Das, S. N. Merchant, and S. S. Yadav, "Infield wireless sensor network (WSN) for estimating evapotranspiration and leaf wetness,” Int. Agric. Eng. J. vol. 18, no. 3-4, pp. 43-51, 2009.

[61] J. M. Gilbert and F. Balouchi, "Comparison of energy harvesting systems for wireless sensor networks," International Journal of automation and computing, vol. 5, no. 4, pp. 334-347, 2008.

[62] F. I. Simjee and P. H. Chou, "Efficient charging of supercapacitors for extended lifetime of wireless sensor nodes," IEEE Trans. Power Electron., vol. 23, no. 3, pp. 1526-1536, 2008.

[63] F. K. Shaikh and S. Zeadally, "Energy harvesting in wireless sensor networks: A comprehensive review," Renewable and Sustainable Energy Reviews, vol. 55, pp. 1041-1054, 2016.

[64] H. M. Jawad, R. Nordin, S. K. Gharghan, A. M. Jawad, and M. Ismail, "Energy-efficient wireless sensor networks for precision agriculture: a review,” Sensors, vol. 17, no. 8, pp. 1781, 2017. 